\title{
Assessment and Modeling of Geo-Spatial Technology and Geo-Spatial Intelligence Support for Joint Military Operations
}

\author{
Nigatu Bekele \\ Ethiopian Defense Force, Joint Military Staff College, Mekele, Ethiopia \\ Email: nigatubekele1983@gmail.com
}

How to cite this paper: Bekele, N. (2019) Assessment and Modeling of Geo-Spatial Technology and Geo-Spatial Intelligence Support for Joint Military Operations. Journal of Geographic Information System, 11, 97-110.

https://doi.org/10.4236/jgis.2019.111008

Received: November 13, 2018

Accepted: February 25, 2019

Published: February 28, 2019

Copyright $\odot 2019$ by author(s) and Scientific Research Publishing Inc. This work is licensed under the Creative Commons Attribution International License (CC BY 4.0).

http://creativecommons.org/licenses/by/4.0/

\begin{abstract}
World military force structure is dramatically changing as collectively; our armed forces undergo a major transition from unprofessional to the Objective Force (designed to capitalize on information-age based technologies and Human Interaction to Non-Human Interaction). Traditional "stovepipes" among services are being eliminated and replaced with integrated systems that allow joint forces (combined Army, Air Force and navy) to seamlessly execute required tasks. This study was undertaken in conjunction with Geospatial Technology (Shows Space and Time) and Geospatial Intelligence Analysis (Use Algorithm, Use AI Concepts, IMINT and GEOINT). In order to successfully support current and future Ethiopian military operations in war zones, geospatial technologies and geospatial intelligence must be integrated to accommodate force structure evolution and mission requirement directives. The intent of joint intelligence operations is to integrate Ground, Air and Navy Forces at war zone and also give COP ("common operational picture") for Operational and Tactical Commander Service and national intelligence capabilities into a unified effort that surpasses any single organizational effort and provides the most accurate and timely intelligence to commanders.
\end{abstract}

\section{Keywords}

Remote Sensing, GIS, GPS, UAVs, High-Resolution Satellite Image

\section{Introduction}

Geospatial technology offers a wide range of innovative and cost effective solutions for environmental sustainability; hence, many countries now appreciate the relevance of geospatial technology in the sustenance of our environment. The relevance of environmental information is based on the degree of its availa- 
bility to the end users and to what extent such information can be shared effectively with external organizations largely over the internet and other available global information infrastructure (SDI) platforms. In this regard, the emphasis should be on accessibility and distribution of available information over a wide range of networks and environmental information market-places [1].

This study was undertaken in conjunction with Geospatial Technology (Shows Space and Time) and Geospatial Intelligence Analysis (Use Algorithm; Use AI Concepts). In order to successfully support current and future Ethiopian military operations in war zones, geospatial technologies and geospatial intelligence must be integrated to accommodate force structure evolution and mission requirement directives. The intent of joint intelligence operations is to integrate Ground, Air and Navy Forces at war zone and also give COP ("common operational picture") for Operational and Tactical Commander. Service and national intelligence capabilities into a unified effort surpass any single organizational effort and provide the most accurate and timely intelligence to commanders [2].

\subsection{Statement of the Problem}

Efficient methods for collecting and integrating geospatial data and effectively generating useful products have not been fully developed and there is no practicable integration of geospatial data-geospatial intelligence-digital maps, images and terrain data-and not yet developed universal model by integrated spatial data.

\subsection{Major Research Objectives}

The major research objectives are assessment and modeling of geospatial information/technology and geospatial intelligence for joint military operations in the combat zone region.

\section{Specific Objectives of My Research}

1) To evaluate geospatial technology/sensor/GPS/satellite/drone.

2) To evaluate geospatial intelligence/process/role/techniques for joint military.

3) To demonstrate the value of a digital geographic information system (GIS) database developed according to military specifications for planning and execution of battlefield operations.

4) To establish example modeling and terrain visualization protocols for battlefield regions, employing design and/or operating functions planned for use as part of the Commercial Joint Mapping Toolkit (C/JMTK).

5) To endorse and share world experience using geospatial technology and intelligence for joint military operation to our unit.

\subsection{Study Area}

Joint operations are conducted from four spatially unique regions-Hydrographic (Sea), Topographic (Land), Aeronautic (air) and (space) [3]. 


\section{Methodology}

A procedure for ranking the image data in terms of potential for extracting features and populating databases was developed. Four basic steps were involved: 1) feature selection; 2) establishment of image evaluation criteria; 3) comparative evaluations of images; 4) consolidation of image evaluations and assessment of results. A procedure for demonstrating the effective use of GIS in generating large-scale products from Joint War databases employing commercial GIS software was developed. Three basic feature steps were involved: 1) database preparation; 2) map product design; 3) development of GIS applications for Joint operations and different types of satellite image had been used in this research (see Table 1).

The prototype should include the following component: 1) A data transmission system to investigate techniques for real-time data acquisition by a GIS server from remote data stations. 2) A model interface to integrate a test model with the data transmission system and Web-based Geospatial Technology. 3) DBMS to establish a suitable database and data processing facilities using a range of technologies. 4) A transparent and flexible user interface to develop a user-friendly interface that facilitates rapid and smooth operation.

\section{Data Used in This Research}

See Table 1.

\section{Result and Discussion}

\section{Objective one: geospatial information use in military operations}

There are numerous critical and advanced image data collection technologies that now define unprecedented military intelligence, surveillance and reconnaissance capabilities. These advances enhance the detectability of features and targets across the littoral battle space, improving distance ranging, "turning" night into day for some classes of operations, reducing the risk of friendly fire incidents (fratricide) and further accelerating operational tempo [4]. On the horizon, improvements in information and systems integration technologies will

Table 1. Data used in this study.

\begin{tabular}{lcccc}
\hline \multicolumn{1}{c}{ Image } & $\begin{array}{c}\text { Spatial } \\
\text { Resolution }\end{array}$ & $\begin{array}{c}\text { Spectral } \\
\text { Bands }\end{array}$ & $\begin{array}{c}\text { Radiometric } \\
\text { Resolution }\end{array}$ & Acquisition \\
\hline Scanned True Color Photography & $0.15 \mathrm{~m}$ & B.G.R & 8 -bit & May 2018 \\
Scanned Color-Infrared & $1.2 \mathrm{~m}$ & B.G.R.IR & 8 -bit & May 2018 \\
Quick Bird Panchromatic & Around 1 m & pan & 8 -bit & May 2018 \\
Ikonos Panchromatic Images & $2.5 \mathrm{~m}$ & B.G.R.IR & 11-bit & June 2018 \\
Ikons Pan-Sharpened Panchromatic Images & $1 \mathrm{~m}$ & Pan & 11-bit & June 2018 \\
Ikonos Multispectral Image & $1 \mathrm{~m}$ & B.G.R.IR & 11-bit & June 2018 \\
Lands at TM panchromatic Images & $4 \mathrm{~m}$ & B.G.R.IR & 11-bit & June 2018 \\
\hline
\end{tabular}


significantly impact future military operations by providing decision makers with accurate information in a timely manner. The fusion of information with the integration of sensors, platforms and command organizations will potentially allow operational tasks to be accomplished rapidly and more efficiently.

\subsection{Geospatial Data Collection Technologies}

Three major data collection categories used in populating GIS databases include 1) Field data collection and GPS; 2) Aerial reconnaissance; 3) Reconnaissance satellite.

\subsubsection{Field Data Collection and GPS}

There are numerous methods of collecting raw data in the field for direct input into Joint warfare geospatial databases. These methods are most often used when the required data do not exist in any other readily available format, such as maps, photographs or satellite images. Field data also are frequently collected when "ground trothing" of remotely sensed data is required. Traditional manual surveying techniques make use of levels and theodolites for directly collecting field measurements. Modern digital equivalents of these manual techniques have been developed so that data collected are stored in digital format ready for direct input into a GIS Examples here include total stations (high-precision theodolites with electronic distance measurement (EDM) and data logger capabilities), hand-held laser range finders and digital compasses

\subsubsection{GPS}

The GPS has a bright future; it is being improved to preserve the advantages it brings to the battlefield and to prevent its vulnerability to attack [5]. Different types of GPSs available for pointing out the spatial area and converts satellite signals into position, velocity and time estimates for navigation, positioning and time dissemination(see Figure 1). Most of the user equipment is employed by more than one service with very few (if any) having utility for a single service.

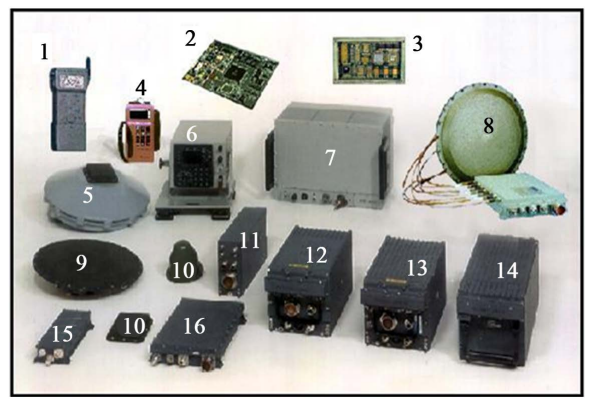

Figure 1. The different Types of GPSs Equipment [6]. 1. Combat survivor/Evader Locator (CSEL); 2. GRAM-SAASM; 3. Selective Availability Anti; 4. Precision Light weight GPS Receiver (PLGR); 5. FRPA Ground Plane (FRPA-GP); 6. Standard Control Display Unit (CDU); 7. Receiver 3S; 8. GPS Antenna system (GAS)-1; 9. Controlled Radiation Pattern Antenna (CRPA); 10. Fixed Radiation Pattern Antenna (FRPA); 11. Miniature Airborne GPS Receiver (MAGR); 12. Receiver OH (MIL-STD-1553); 13. Receiver UH (ARINC-429); 14. Receiver 3A; 15. Antenna Electronics AE-1/AE-1A; 16. Antenna Electronics AE-4. 
The above GPS user equipment segment consists of the military GPS receivers, antennae and other GPS-related equipment. Global positioning system receivers are used on aircraft, ships at sea, ground vehicles or hand-carried by individuals.

\subsubsection{Digital Images}

Another popular technology, imaging spectroscopy (also known as hyper spectral remote sensing) allows a sensor on a moving platform to gather reflected radiation from ground targets where a special detector system records up to $200+$ spectral channels simultaneously over a range from 0.38 to $2.5 \mu \mathrm{m}$ [5]. With such detail, the ability to detect, intercepts, and identify individual materials or classes greatly improves by cascading GPS with laptops (see Figure 2(a)). Airborne Visible/Infrared Imaging Spectrometer (AVIRIS), one such hyper spectral sensor, operated since 1987, consists of four spectrometers with a total of 224 individual bandwidths, each with a spectral resolution of $10 \mathrm{~nm}$ and a spatial resolution of $20 \mathrm{~m}$ [6]. A new form of PDAs display digital imagery, light detection and ranging (lidar) is a very powerful and versatile remote sensing display tools (see Figure 2(b)). It has a broad range of applications and is extremely well suited for coastal zone monitoring. One noteworthy application of lidar technology is the Scanning Hydrographic Operational Airborne Lidar Survey (SHOALS) system [7]. This bathymetric mapping application uses a technique known as airborne lidar bathymetry (ALB) or airborne lidar hydrography (ALH).

\subsubsection{Sensor Data Obtained with UAVs}

The predator was designed to provide follow-on, interim support to Army tactical commanders with near-real-time imagery intelligence at ranges up to 200 $\mathrm{km}$ (see Figure 3(a)). This system, still in limited use, helped developers create the systems' capabilities requirement for future TUAV design (Figure 4). The resulting product, now in extensive use, was the Joint Tactical UAV or Hunter. Hawak UAVs was developed to provide ground and maritime forces with

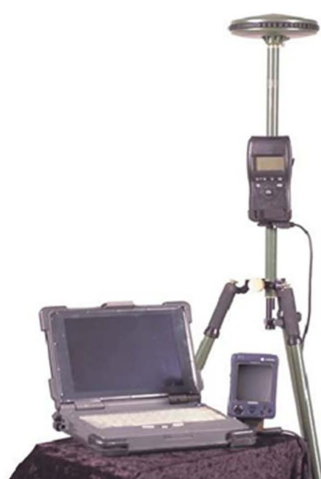

(a)

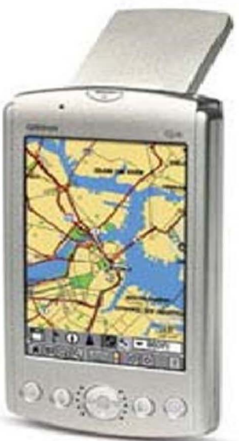

(b)

Figure 2. (a) Military GPS portability on laptops (left) and (b) PDAs Aerial Reconnaissance. The above figure shows how to integrated GPS receiver, Laptop and Display device. 


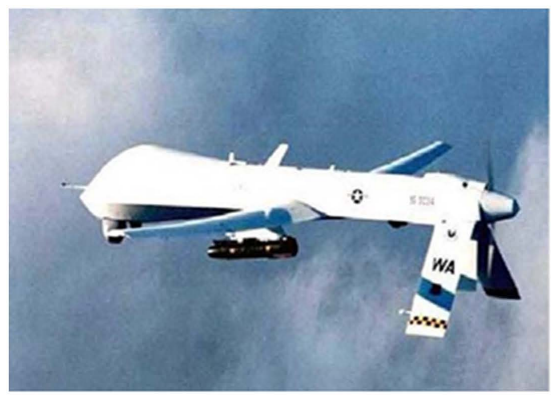

(a)

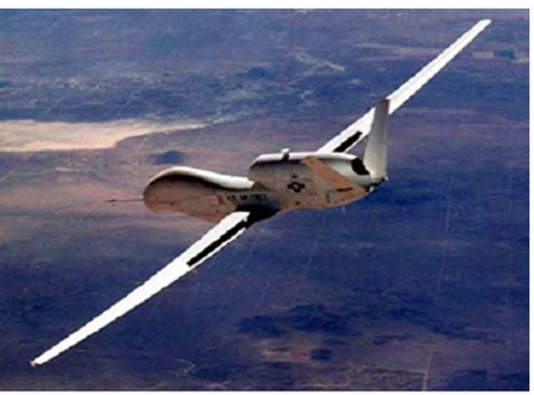

(b)

Figure 3. (a) The Predator and (b) Global Hawk endurance UAVs [7]. The figure shows how born system capturing data from earth space.

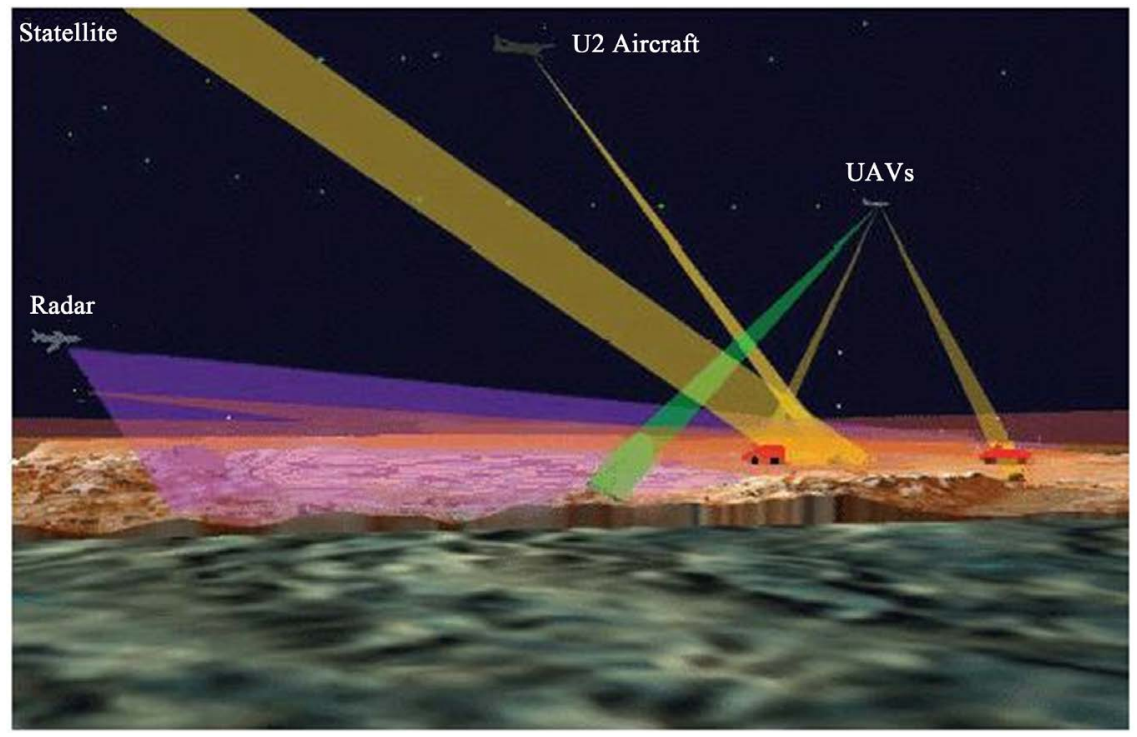

Figure 4. Integration of Geospatial Information and Intelligence [7]. The figure shows the integration of UAV, Satellite, and Aircraft.

real-time and near-real-time imagery intelligence at ranges up to $200 \mathrm{~km}$ and extensible to $300+\mathrm{km}$ by using another Hunter as an airborne relay (see Figure $3(\mathrm{~b})$ ).

\section{The integration of data from space borne and airborne systems}

Although the use of aerial photographs and digital images for littoral applications has seen modest increase over the past few years, UAV exploitation has grown tremendously. The ability to provide real-time or near real-time data about the terrain they fight on and the enemy they face has a Joint War has been a goal of the military intelligence community [8]. Unmanned aerial vehicles have made that goal a reality at many levels of war, becoming a valuable tool for $\mathrm{Ar}$ my and Marine Corps planners and ground commanders in preparation and execution of missions by integrating UAV, Satellite, and Aircraft (see Figure 4). Moreover, increasingly more UAVs populating the littoral battle space, coupled with robust communications systems for distribution of the information they gather, these data may soon be available to every soldier and marine. Micro un- 
manned aerial vehicles (MAV) are currently under development. Experiments are being conducted to explore the military relevance of MAVs for future operations and to develop and demonstrate flight-enabling technologies for very small aircraft (less than $15 \mathrm{~cm}$ in any dimension) [9]. As portable systems capable of receiving and utilizing image data proliferate the littoral battlefield, data volume will continue to be a challenge. Communication systems designed to monitor, control and filter bandwidth at different levels of war fighting (strategic, operational or tactical) will play critical roles in "moving" the data.

Unmanned aerial vehicles are remotely piloted or self-piloted aircraft that carry cameras, sensors, communications equipment or other payloads [9]. Not a new idea, the UAV has been employed by military units since the late 1950s [10]. Until the last 15 years, however, their usefulness was viewed as limited because the analog data they collected were not accessible (in most all cases) until after they returned from their missions. Digital technology changed this paradigm. As a result, since the early 1990s, DoD has employed UAVs to satisfy surveillance requirements in close range, short range and endurance categories. Initially, close range was defined to be within $50 \mathrm{~km}$; short range was defined as within $200 \mathrm{~km}$; and endurance range was set as anything beyond. By the late 1990s, the close and short range categories were combined. The current classes of these vehicles are the tactical UAV and the endurance category.

Numerous digital multispectral, hyper spectral and radar sensor platforms are used on-board both tactical and endurance UAVs for military applications in littoral regions. As the ability to move data quicker and in greater volume improves, military commanders now receive current details of battlefield events like never before. Commanders are trained warfighters; they have a basic understanding of aerial photos/video, but are not trained in the interpretation of IR and radar data. For simple utility purposes, much of the tactical data gathered for military use by these systems are high-resolution multispectral images, predominantly from the visual portion of the electromagnetic spectrum. Average spatial ground resolutions now routinely achieved by these systems are on the order of one meter. Systems collecting IR, thermal and radar data are quickly approaching similar resolutions [11].

In all cases of UAV employment, tactical control stations (TCS) are used to control the vehicles and their on-board systems. The TCS is the hub where all software and communications links reside as well as connectivity links to other battlefield command, control, communication, computers and intelligence (C4I) systems [12].

\subsubsection{Satellite Reconnaissance}

There are a growing number of satellites orbiting the earth, collecting important data and returning it to ground stations all over the world. Space born Satellite remote sensing has the ability to provide complete, cost-effective, repetitive spatial and temporal data coverage (see Figure 5). Tasks such as the assessment and 


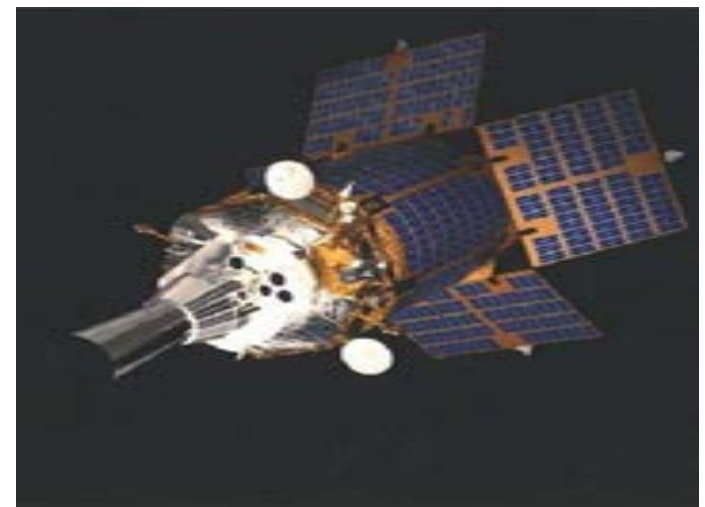

Figure 5. The integration of data from space borne [7]. The figure shows accessing data from air by using Space born.

monitoring of littoral conditions can be carried out over large regions. Classified and, increasingly, unclassified, systems have and continue to be successfully used by intelligence organizations to provide critical information to military units.

Airborne Satellite imaging systems have long been the workhorse of the military intelligence community. Moreover, airborne system systems are primarily used for the collection of intelligence information about military activities of foreign countries (see Figure 6).

These satellites can detect missile launches or nuclear explosions in space and acquire/record radio and radar transmissions while passing over other nations (see Figure 7). There are four basic types of reconnaissance satellites: 1) optical-imaging satellites that have light sensors designed to detect enemy weapons on the ground; 2) radar-imaging satellites that are able to observe the Earth through cloud cover; 3) signals-intelligence or ferret satellites that are sophisticated radio receivers capturing the radio and microwave transmissions emitted from any country on Earth; 4) relay satellites that make military satellite communications around the globe much faster by transmitting data from spy satellites to stations on Earth [13].

\section{Conclusions from literature review}

There are numerous critical and advanced image data collection technologies that now define unprecedented military intelligence, surveillance and reconnaissance capabilities. These advances enhance the detectability of features and targets across the littoral battle space, improving distance ranging, "turning" night into day for some classes of operations, reducing the risk of friendly fire incidents (fratricide) and further accelerating operational tempo [14]. On the horizon, improvements in information and systems integration technologies will significantly impact future military operations by providing decision makers with accurate information in a timely manner. The fusion of information with the integration of sensors, platforms and command organizations will potentially allow operational tasks to be accomplished rapidly and more efficiently. The GPS user equipment segment consists of the military GPS receivers, antennae and other GPS-related equipment. Global positioning system receivers are used 


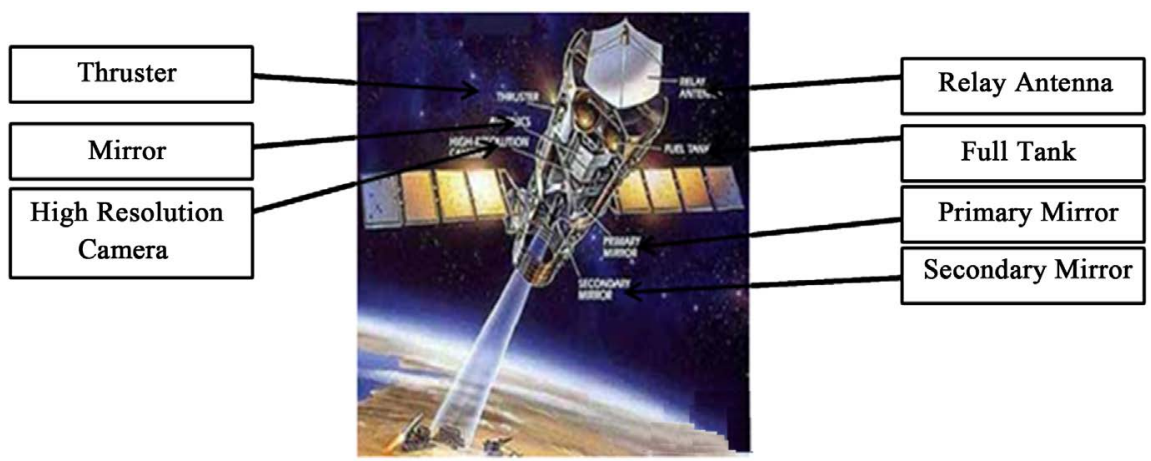

Figure 6. Airborne systems [7]. The figure shows airborne systems used to collecting intelligence information from community.

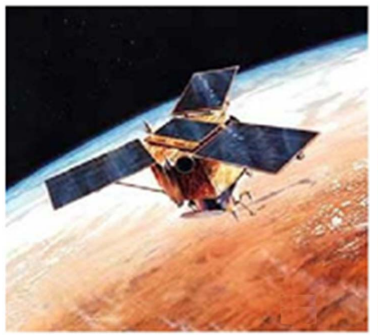

(a)

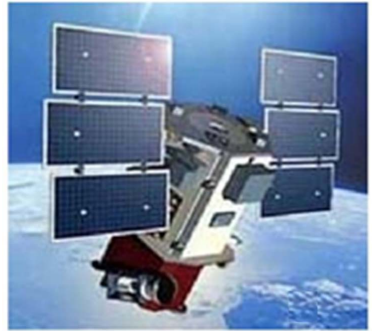

(b)

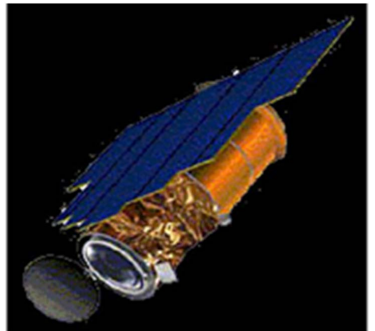

(c)

Figure 7. Left to right: (a) Ikonos; Quick Bird; (b); (c) OrbView-3 high-resolution satellites [7]. The figure shows the different types of satellite used to detect missile launches or nuclear explosions in space and radio transmission.

on aircraft, ships at sea, ground vehicles or hand-carried by individuals. They convert satellite signals into position, velocity and time estimates for navigation, positioning and time dissemination. Most of the user equipment is employed by more than one service with very few (if any) having utility for a single service.

\section{Objective two: evaluation of geospatial intelligence for joint military}

The unique mix of technology, data, and analytics that is used in the decision making processes in the defense, intelligence, security, and humanitarian fields is known as geospatial intelligence, and the World Geospatial Intelligence Foundation has become a leader in advocating for geospatial intelligence as the career most equipped to address the challenges of these industries. Going beyond data analysis and technology use, geospatial intelligence applies established principles, tools, and techniques to analyze the changing patterns of human activity to solve real-world problems. The goal is to better predict future outcomes and location-based decisions. Geospatial intelligence (GEOINT) operations include the tasks, activities, and events used to collect, manage, analyze, generate, visualize, and provide the imagery, imagery intelligence, and geospatial information necessary to support national and defense missions as well as international arrangements [15].

Geospatial intelligence (GEOINT) is defined "the exploitation and analysis of imagery and geospatial information to describe, assess, and visually depict phys- 
ical features and geographically referenced activities on the Earth. GEOINT consists of imagery, imagery intelligence (IMINT), and geospatial information intelligence process (Dissemination and integration, Planning and directing, collection, processing and exploitation and Analysis and production geospatial data (see Figure 8). Any one or combination of these three GEOINT elements may be considered GEOINT. The full utility of GEOINT comes from the integration and use of imagery, IMINT, and geospatial information, enabling customers to gain a more comprehensive perspective, an in-depth understanding, and a cross-functional awareness of the operational environment (OE) [16].

\section{Database preparation}

ArcGIS provides an open, interoperable platform that underpins capabilities in each defense domain. By doing this, ArcGIS is also capable of connecting the domains-critically important in today's defense and intelligence environment where boundaries between facilities, war fighting, and strategic intelligence are increasingly blurred. Consider, for example, the intelligence analyst trying to assess terrorist intentions against a forward deployed air force base.

The ArcGIS Data Interoperability extension enhances the data access capabilities of the ArcGIS Desktop products by providing access to many more data formats through direct read, translation, and transformation. The extension enables users to directly read and import more than 70 spatial data formats and export to more than 50 . Users also have the ability to define custom data formats within an interactive, visual diagramming environment. ArcGIS Data Interoperability is built on Safe Software's industry-standard Feature Manipulation Engine product this is a significant capability for desktop product users in all defense domains. It dramatically enhances the ability to fuse spatial information from a wide range of proprietary and:

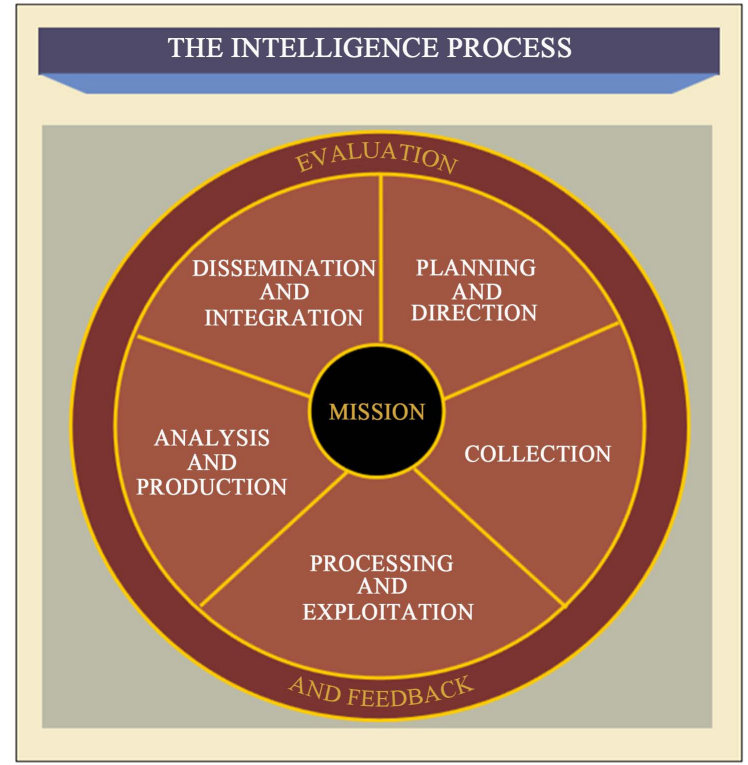

Figure 8. The geospatial intelligence operations process [8]. The figure shows the overall GEOINT Process which is used for intelligence system. 
Extract GEO-Spatial Technology (GIS) for Military Operations (Intelligence, Surveillance, and Reconnaissance-Battle space Awareness)

ISR involves merging all sensors in the battle space into spatially aware databases (geo-databases) across networks to help decision makers and war fighters understand the current situation (common operational picture/common tactical picture). ArcGIS provides a critical infrastructure for ISR because it retains the spatial context of the sensors and maintains the relationships between sensors and other battle space entities and actions within the geo-databases. GIS is a naturally integrating technology, and fusion will occur naturally because the spatial context is maintained.

Command, control, communications, computers, and intelligence assessment-to tell

The C4I domain supports timelier and better decisions by using a variety of tools to analyze, assess, and plan actions. ArcGIS bolsters C4I capabilities by providing a common spatial context and the tools to provide decision makers, commanders, and warfighters with a distributed, scalable, decision support environment

Precision engagement-to strike

PE includes the coordination of strike assets in time and space to achieve the commander's desired effect. ArcGIS provides the information framework and tools to understand time and space activities and constraints, and then assists in passing precise information to the engagement systems ArcGIS also provides a critical information structure that connects the concepts of NCO. This common foundation permits the spatial context of data to flow as information for ISR to C4I and as actions from C4I to PE. ArcGIS provides the framework for storage, dissemination, and exploitation of battle space knowledge throughout the defense and intelligence infrastructure.

\section{Model interpretations}

All three environments-sea, land and air-merit the attention of Marine commanders. Shoreline delineations provide improved maps of intertidal zones at large-scale, detailing how tide levels will impact amphibious operations. Perspective scene modeling of these shorelines reveals overland flow of tidal waters at LPPs, enabling 3-D visualizations of water levels from which conclusions about mission impacts can be made. Effective vehicle traffic ability estimates are critical information as well. Geographic information system functions enable the analysis of data vital to the development and generation of these products. In this regard, proper GIS database construction and data modeling are necessary to assist commanders in route and/or attack axis selection. Finally, aerial perspective scenes and simulated "fly-overs" provide a realistic view of the landscape by draping properly rectified satellite or aerial images over co-registered, detailed and accurate DEMs [17]. These products are quickly compared to real-time (or near real-time) video and scenes collected by UAVs and/or satellite images. Analysis and modeling capabilities of a GIS provide military commanders the means to rapidly integrate data sets, assess conditions, plan strategies and eva- 
luate options. The overall success and reliability of large-scale, JOINT WARD products created from.

Objective four: to recommend and share world experience using geospatial technology and intelligence for joint military operation

"See-understand-act-finish"

Seeing and understanding first gives commanders and their units the situational awareness to engage at times and places with methods of their own choosing. Objective Force units will be able to move, shoot and reengage faster than the enemy. It is planned that target acquisition systems will see farther than the enemy in all conditions and environments. The intent, here, is to deny the enemy any respite or opportunity to regain the initiative. Objective Force units will be able to understand the impact of events and synchronize their own actions. Finally, Objective Force units should finish decisively by quickly destroying the enemy's ability to continue the fight. Units will be able to maneuver by both ground and air to assume tactical and operational positions of advantage through which they will continue to fight the enemy and pursue subsequent military objectives. Although these advances will not eliminate battlefield confusion, the resulting battle space awareness should improve situational knowledge, decrease response time, and make the battlefield considerably more transparent to those who achieve it. The integration of geospatial technology

\section{Conclusions and Recommendation}

\subsection{Conclusions}

- This research focused on developing methodologies of employing geospatial information for defining unprecedented military intelligence, surveillance and reconnaissance capabilities. Joint military operations were in the battle region. There are many advanced data collection technologies.

- Three of these-GPS, sensors on UAVs and high-resolution satellite images-enhance the detectability of features and targets across the War battle space, improve distance estimation, reduce the risk of fratricide and further the speed of operations.

- A number of studies have addressed independent digital solutions that make limited use of these data for military needs. However, methods for efficient collection and integration of the information and effective generation of useful military decision-making tools have not been fully developed. It is envisioned that the work undertaken for this dissertation will help provide answers to what information the data provide and to how the military can best use that information.

- The integration of geospatial technologies and GIS will likely provide an improvement in lethality. Commanders will be able to attack targets successfully with fewer platforms and less ordnance while achieving objectives more rapidly and with reduced risk. Strategically, this improvement will enable more rapid power projection. 
- Operationally, within the theater, these capabilities will mean a more rapid transition from deployment to full operational capability. Tactically, individual war fighters will be empowered as never before, with an array of detection, targeting and communications equipment that will greatly magnify the power of small units. As a result, military force will improve. Forces will improve their capability for rapid and worldwide deployment while becoming even more tactically mobile and effective.

\subsection{Recommendations}

- Ethiopian Defense should use geospatial technology for better acquisition of Military Information.

- In order to successfully support future military operations, important planning tools must be integrated to accommodate both force structure evolution and mission requirement directives. My work examined this integration, addressed the critical challenges brought about by change and proposed realistic solutions for the use of geospatial information in the future.

- This research provided examples of improved digital data sets, map products and procedures that can be used by NGA for future military applications in War zones. It is anticipated that further research with database and software platforms will continue to result in more efficient and productive solutions for ongoing mapping and modeling challenges of military operations in the coastal environment.

- Military leaders should use GIS and GPS (Global Positioning Systems) to make tactical decisions such guiding troops, supplies/equipment and ships, informing them of possible threats, problems with terrain in which they will encounter and also to direct their attention to specific areas of interests. For example data is relayed to cockpit of attack aircraft giving the pilot needed information, such the location of target and identification of the target, plus possible hot spots in which they may encounter an attack on themselves. These pilots also receive data on meteorological information, which enhances visibility, and pre warns them of possible change, which may occur during an aerial activity.

- Future GEOSPA AND GEOINT processes should be designed and constructed to use the standards-based definitions for Geospatial Core Types.

- Creation of national Geospatial intelligence agency or unit in the military for effective coordination in Ethiopian military.

- All military schools should be offering courses related to surveying and GIS.

\section{Conflicts of Interest}

The author declares no conflicts of interest regarding the publication of this paper.

\section{References}

[1] Aronoff, S. (1991) Geographic Information Systems: A Management Perspective. 
WDL Publications, Ottawa, 294 p.

[2] Ballendorf, D.A. (2003) The Battle for Tarawa: A Validation of the WORLD. Marines.

[3] Behling, T. and McGruther, K. (1998) Satellite Reconnaissance of the Future. Joint Forces Quarterly, Spring Edition, 23-30.

[4] Birdwell, T., Klemunes, J. and Oimoen, D. (2004) Tracking the Dirty Battlefield during Operation Iraqi Freedom with the Tactical Minefield Database. Mil Intel Muster, Winter 2003/2004 Edition, Environmental Systems Research Institute (ESRI), Redlands, $11 \mathrm{p}$.

[5] Bolstad, P. (2004) GIS Fundamentals. University of Minnesota, St. Paul.

[6] Braud, D.H. and Feng, W. (1998) Semi-Automated Construction of the Louisiana Coastline Digital Land/Water Boundary Using Landsat TM Satellite Imagery. Department of Geography \& Anthropology, Louisiana State University, Louisiana Applied Oil Spill Research and Development Program, OSRAPD Technical Report Series 97-002.

[7] Burrough, P.A. and McDonnell, R.A. (1998) Principles of Geographical InformationSystems. Oxford University Press, Oxford, 333 p.

[8] Caton, J. (1995) Joint Warfare and Military Dependence on Space. Joint Forces Quarterly, Winter Edition, 48-53.

[9] Chan, K. (1999) DIGEST-A Primer for the International GIS Standard. CRC Press LLC, Boca Raton 128 p.

[10] Cole, R.H. (1998) Grenada, Panama and Haiti: Joint Operational Reform. Joint Forces Quarterly, Autumn/Winter Edition, 57-64.

[11] Comer, R., Kinn, G., Light, D. and Mondello, C. (1998) Talking Digital. Photogrammetric Engineering and Remote Sensing, 64, 1139-1142.

[12] JCS (Office of the Chairman of the Joint Chiefs of Staff) (1997) JV2010. The Pentagon, Washington DC, $35 \mathrm{p}$.

[13] JCS (Office of the Chairman of the Joint Chiefs of Staff) (1999) Joint Pub 2-03: Joint Tactics, Techniques, and Procedures for Geospatial Information and Services Support to Joint Operations. The Pentagon, Washington DC, $72 \mathrm{p}$.

[14] JPL (Jet Propulsion Laboratory) (2004) AVIRIS. California Institute of Technology, Pasadena.

[15] Kimble, K. and Veit, R. (2000) SPACE-The Next Area of Responsibility. Joint Forces Quarterly, Autumn/Winter Edition, 20-23.

[16] Krulak, C. (1999) Operational Maneuver from the Sea. Joint Forces Quarterly, Spring Edition, 78-86.

[17] Leica Geosytems (2004) RC30 Aerial Camera System. Leica Geosytems Worldwide Headquarters, Atlanta. 